\title{
Characterization of a novel orthoreovirus isolated from fruit bat, China
}

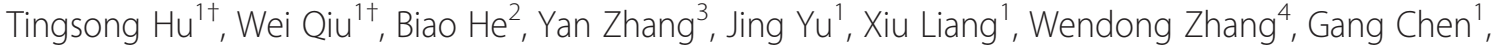 \\ Yingguo Zhang ${ }^{4}$, Yiyin Wang ${ }^{1}$, Ying Zheng ${ }^{1}$, Ziliang Feng ${ }^{1}$, Yonghe $\mathrm{Hu}^{5}$, Weiguo Zhou ${ }^{1}$, Changchun $\mathrm{Tu}^{2}$, \\ Quanshui Fan ${ }^{1 *}$ and Fuqiang Zhang ${ }^{1 *}$
}

\begin{abstract}
Background: In recent years novel human respiratory disease agents have been described for Southeast Asia and Australia. The causative pathogens were classified as pteropine orthoreoviruses with a strong phylogenetic relationship to orthoreoviruses of bat origin.

Results: In this report, we isolated a novel Melaka-like reovirus (named "Cangyuan virus") from intestinal content samples of one fruit bat residing in China's Yunnan province. Phylogenetic analysis of the whole Cangyuan virus genome sequences of segments $L, M$ and $S$ demonstrated the genetic diversity of the Cangyuan virus. In contrast to the $\mathrm{L}$ and $\mathrm{M}$ segments, the phylogenetic trees for the $\mathrm{S}$ segments of Cangyuan virus demonstrated a greater degree of heterogeneity.

Conclusions: Phylogenetic analysis indicated that the Cangyuan virus was a novel orthoreovirus and substantially different from currently known members of Pteropine orthoreovirus (PRV) species group.
\end{abstract}

Keywords: Bat Orthoreovirus, Prevalence, Viral genome reassortment

\section{Background}

Many emerging infectious diseases are caused by zoonotic transmission, and the consequence is often unpredictable. Zoonoses have been well represented with the 2003 outbreak of severe acute respiratory syndrome (SARS) due to a novel coronavirus [1,2]. Bats are associated with an increasing number of emerging and reemerging viruses, many of which pose major threats to public health, in part because they are mammals which roost together in large populations and can fly over vast geographical distances $[3,4]$. Many distinct viruses have been isolated or detected (molecular) from bats including representatives from families Rhabdoviridae, Paramyxoviridae, Coronaviridae, Togaviridae, Flaviviridae, Bunyaviridae, Reoviridae, Arenaviridae, Herpesviridae, Picornaviridae, Filoviridae, Hepadnaviridae and Orthomyxoviridae [3-8].

\footnotetext{
*Correspondence: fqs168@126.com; zfq1968@aliyun.com

${ }^{\dagger}$ Equal contributors

${ }^{1}$ Centre for Disease Control and Prevention, Chengdu Military Region, 168 Daguan Road, Kunming 650032, China

Full list of author information is available at the end of the article
}

The Reoviridae (respiratory enteric orphan viruses) comprise a large and diverse group of nonenveloped viruses containing a genome of segmented double-stranded RNA, and are taxonomically classified into 10 genera [9-13]. Orthoreoviruses are divided into two subgroups, fusogenic and nonfusogenic, depending on their ability to cause syncytium formation in cell culture, and have been isolated from a broad range of mammalian, avian, and reptilian hosts [10-14]. Members of the genus Orthoreovirus contain a genome with 10 segments of dsRNA; 3 large (L1-L3), 3 medium (M1-M3), and 4 small (S1 to S4) [15].

The discovery of Melaka and Kampar viruses, two novel fusogenic reoviruses of bat origin, marked the emergence of orthoreoviruses capable of causing acute respiratory disease in humans $[9,16]$. Subsequently, other related strains of bat-associated orthoreoviruses have also been reported, including Xi River virus from China $[17,18]$. Wong et al. isolated and characterized 3 fusogenic orthoreoviruses from three travelers who had returned from Indonesia to Hong Kong during 2007$2010[19,20]$. 
In the present study we isolated a novel reovirus from intestinal contents taken from one fruit bat ( Rousettus leschenaultia) in Yunnan province, China. In the absence of targeted sequencing protocols for a novel virus, we applied the VIDISCR (Virus-Discovery-cDNA RAPD) virus discovery strategy to confirm and identify a novel Melaka-like reovirus, the "Cangyuan virus". To track virus evolution and to provide evidence of genetic reassortment PCR sequencing was conducted on each of the 10 genome segments, and phylogenetic analysis performed to determine genetic relatedness with other bat-borne fusogenic orthoreoviruses.

\section{Results}

\section{Virus isolation and morphological characterization}

The Vero-E6 cells showed a syncytial cytopathic effect (CPE) after 24 hours of the first inoculation at $37^{\circ} \mathrm{C}$ (Figure 1). The virus was named "Cangyuan virus" after the location from which the host bats (Rousettus leschenaultia) were collected (Cangyuan city of Yunnan province, China). After the first passage in Vero E6 cells, Cangyuan virus began to cause syncytial CPE 24 hours post-inoculation; notably earlier than for Melaka virus and other orthoreovirus (Figure 1B) $[9,16,17,20]$. QPCR analysis demonstrated that the replication of Cangyuan virus began after 12 hours infected the Vero E6 cells (Figure 1C).
After the second passage, Virus titrations were performed and the infectious dose of Cangyuan virus was $10^{5.5}$ TCID50/0.1 ml. QPCR analysis demonstrated that Cangyuan virus is the virus replicating in the cells and responsible for the observed CPE (Table 1).

Negative-staining EM of particles in the supernatant recovered from Vero E6 cells infected with Cangyuan virus revealed non-enveloped icosahedral virus-like particles, approximately $70-80 \mathrm{~nm}$ in diameter, possessing a double capsid with conspicuous "spikes" or "turrets" situated on the inner core; features characteristic of the family Reoviridae, genus Orthoreovirus (Figure 1D) [9].

\section{Neutralizing antibody titers}

Serum samples from 50 fruit bats ( Rousettus leschenaultia) collected from Cangyuan city were screened for antiCangyuan virus neutralizing antibody. According to the Neutralizing Antibody Titers determined in this study, the serum of two bats had a neutralizing antibody titer of 1,280 against Cangyuan virus and the serum of five bats $(10 \%, 5 / 50)$ a titer of 640 against Cangyuan virus. Our studies indicated a $26 \%(13 / 50)$ prevalence for antibody titers $>1: 160$ for Cangyuan virus-specific antibodies in fruit bats (Rousettus leschenaultia). The control serum had a neutralizing antibody titer $<10$. At present, it is not clear whether Cangyuan virus is carried by a
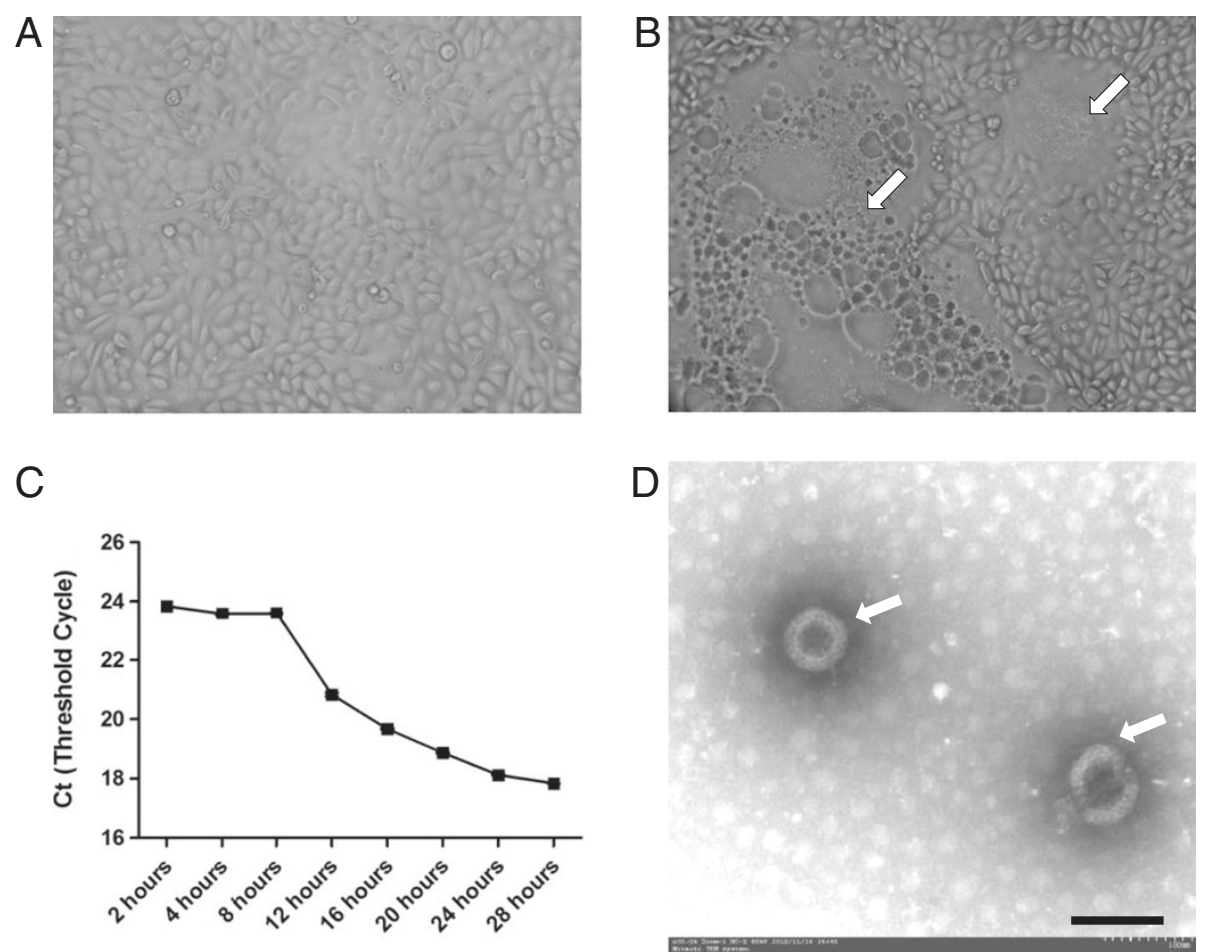

Figure 1 Syncytium formation in Cangyuan virus-infected Vero E6 cells. (A) Mock-infected. (B) Cangyuan virus -24 hours post-infection. (C) The viral growth curve of Cangyuan virus infected VeroE6 cells in the 28 hours. (D) Negatively stained electron micrograph of viral particles (arrowheads) recovered from the supernatant of Cangyuan virus-infected Vero E6 cells. Bar $=100 \mathrm{~nm}$. 
Table 1 QPCRs result of Cangyuan virus infected VeroE6 cells with the $\mathbf{L} 2$ segment primers

\begin{tabular}{lll}
\hline $\begin{array}{l}\text { Cangyuan virus infected VeroE6 } \\
\text { cells ( TCID50/0.1 } \mathbf{~ L L})\end{array}$ & $\begin{array}{l}\text { Average of Ct } \\
\text { (Threshold Cycle) }\end{array}$ & $\begin{array}{l}\text { Time of } \\
\text { CPE (hours) }\end{array}$ \\
\hline $10^{5.5}$ & $16.667 \pm 0.046$ & 16 \\
$10^{4.5}$ & $17.957 \pm 0.811$ & 24 \\
$10^{3.5}$ & $20.273 \pm 0.448$ & 24 \\
$10^{2.5}$ & $22.817 \pm 0.358$ & 24 \\
\hline
\end{tabular}

Note: The culture supernatants $0.1 \mathrm{~mL}$ (after the second passage, $10^{5.5} \mathrm{TCID} 50 /$ $0.1 \mathrm{~mL}$ titer) was serially diluted until $10^{-3}$ and infected Vero E6 cells. After the 24 hours, the culture supernatants were analyzed by RT-QPCRs. The normal Vero-E6 cells as negative controls for RT-QPCRs.

specific fruit bat species or by multiple bat species circulating in the region. A preliminary survey of bat sera collected in Cangyuan city of Yunnan province from our previous studies indicated a low prevalence of Cangyuan virus-specific antibodies in at least two different insectivorous bat species: Rhinolophus luctus $(1 / 23$, Antibody Titers $=1: 320)$ and Small leaf-nosed bat (Hipposideros pomona) $(1 / 30$, Antibody Titers $=$ $1: 160)$.

\section{QPCR, nucleotide sequences and phylogeny}

PCRs testing were repeated on the 50 fruit bats original samples including the Kidney, heart, lung, liver, spleen, intestine, rectal swab sample, and brain samples. Two bat's QPCRs results were positive. One bat's QPCRs result was positive in the lung, intestine sample (Cangyuan virus isolated) and rectal swab sample, and the $\mathrm{Ct}$ (Threshold Cycle) of QPCR were 19.86 $\pm 0.056,19.52 \pm$ $0.041,19.64 \pm 0.061$ respectively. The Ct of another bat's PCR were $23.07 \pm 0.253,22.53 \pm 0.171$ in the intestine sample and rectal swab sample, respectively.

To establish the evolutionary relationship between Cangyuan virus and other known orthoreoviruses, Homology were compared (Table 2, Table 3 and Additional file 1: Table S1, Additional file 2: Table S2 and Additional file 3: Table S3) and phylogenetic trees were constructed based on the nucleotide sequences of the $\mathrm{L}$ genome segments (Figure 2), the $\mathrm{M}$ genome segments (Figure 3) and the $\mathrm{S}$ genome segments (Figure 4). The Cangyuan virus L1-L3, M1-M3 segments sequence identity were $81.6 \%$ 94.2\%, 83.8\%-97.9\%, 85.9\%-97.6\% ( Additional file 1: Table S1), $82.2 \%-94.1 \%, 78.1 \%-95.0 \%$, and $83.0 \%-$ 93.9\% (Table 2, Additional file 2: Table 2), respectively, by alignment with Pteropine orthoreovirus (PRV) species group. The phylogenetic trees for L2, L3, M1 and M2 segments demonstrated that Cangyuan virus was most closely related to Melaka and Kampar viruses, and was placed in Pteropine orthoreovirus (PRV) species group which covers all known bat-borne orthoreoviruses together with Nelson Bay orthoreovirus $[12,15,21]$.
To better understand the genetic relatedness of Cangyuan virus to other known bat-borne orthoreoviruses, the published sequences for the $\mathrm{S}$ genome segment of bat-borne orthoreoviruses known for causing acute respiratory disease in humans were retrieved from GenBank and used to compare homology (Table 3 and Additional file 2: Table S2) and construct phylogenetic trees (Figure 4). The Cangyuan virus S1-S4 segments sequence identity were $55.3 \%-94.7 \%$, 86.2\%$95.5 \%, 86.5 \%-97.9 \% \%$, and $83.5 \%-98.2 \%$, respectively (Table 3 and Additional file 2: Table S2). The S1 segment demonstrated a greater heterogeneity than other $\mathrm{S}$ segments in Pteropine orthoreovirus (PRV) species group.

\section{Discussion}

The discovery of Melaka and Kampar viruses provide evidence that a novel group of fusogenic orthoreoviruses of bat origin are associated with acute respiratory disease in humans $[9,16]$. To date, there have been six confirmed outbreaks of human respiratory illness caused by this group of viruses; three in Malaysia and three in Bali/Hong Kong $[9,16,17,19,20]$. Despite a lack of direct epidemiological and clinical evidence to support the novel Cangyuan orthoreovirus of bat origin isolated in this study as a causative agent of human respiratory tract infections in China, the genetic relatedness between Cangyuan virus and the Melaka and Kampar viruses implies that it may be a zoonotic infectious agent of clinical significance to human health.

One possibility for potential virulence in humans is genome segment reassortment, which is common among segmented RNA viruses, including the reoviruses $[9,15,20]$. Reassortment has been reported for avian and mammalian reoviruses [22-25]. Phylogenetic analysis of the full sequences of segments $\mathrm{L}, \mathrm{M}$ and $\mathrm{S}$ demonstrated the genetic diversity of the Cangyuan virus.

As summarized above and in Figure 2, 3 and 4, the phylogenetic trees derived from the $\mathrm{S}$ segments demonstrated a greater heterogeneity than those derived for the corresponding $\mathrm{L}$ and $\mathrm{M}$ segments (Table 2, Table 3 and Additional file 2: Table S1, Additional file 2: Table S2 and Additional file 3: Table S3). All four possible topologies were observed for the $\mathrm{S}$ segments of the ten strains: Cangyuan virus was clustered with the Pulau virus (S1: the S1 virus cell attachment protein); Cangyuan virus and Melaka virus clustered together (S2: the S2 major inner capsid protein); Cangyuan virus and Xi river virus together (S3: the S3 nonstructural protein); and Cangyuan virus clustered with Sikamat virus (S4: the S4 Major component of outer capsid).

The distinctive topology pattern of the phylogenetic tree based on the M2 segments (Major outer-capsid protein) is especially interesting and may indicate two 
Table 2 Homology matrix of Cangyuan virus's M2 gene segment with other fusogenic orthoreoviruses

\begin{tabular}{|c|c|c|c|c|c|c|c|c|c|c|c|c|c|c|}
\hline & Homolc & gy mat & ix of $\mathrm{Ca}$ & gyuan & irus's $M$ & gene st & gement & vith othe & fusoge & nic orthe & reovirus & & & \\
\hline ARV138-AY750052_M2 & $100 \%$ & & & & & & & & & & & & & \\
\hline ARV1733-AY635938_M2 & $86.6 \%$ & $100 \%$ & & & & & & & & & & & & \\
\hline ARV176-AY750053_M2 & $90.0 \%$ & $95.7 \%$ & $100 \%$ & & & & & & & & & & & \\
\hline ARVS1133-DQ300177_M2 & $86.4 \%$ & $98.6 \%$ & $95.3 \%$ & $100 \%$ & & & & & & & & & & \\
\hline Cangyuan-KC994907_M2 & $64.3 \%$ & $64.0 \%$ & $63.4 \%$ & $63.7 \%$ & $100 \%$ & & & & & & & & & \\
\hline DRVS14-DQ989557_M2 & $68.9 \%$ & $68.7 \%$ & $68.6 \%$ & $68.8 \%$ & $61.3 \%$ & $100 \%$ & & & & & & & & \\
\hline Kampar-JF342658_M2 & $64.1 \%$ & $63.4 \%$ & $63.2 \%$ & $63.2 \%$ & $95.0 \%$ & $61.5 \%$ & $100 \%$ & & & & & & & \\
\hline Melaka-JF342664_M2 & $63.8 \%$ & $62.6 \%$ & $62.4 \%$ & $62.3 \%$ & $79.2 \%$ & $61.3 \%$ & $78.9 \%$ & $100 \%$ & & & & & & \\
\hline MRV1TL-NC004262_M2 & $50.4 \%$ & $50.4 \%$ & $50.4 \%$ & $50.2 \%$ & $49.9 \%$ & $49.3 \%$ & $49.4 \%$ & $49.2 \%$ & $100 \%$ & & & & & \\
\hline MRV3TD-EF494439_M2 & $50.5 \%$ & $50.4 \%$ & $50.4 \%$ & $50.3 \%$ & $49.7 \%$ & $49.2 \%$ & $49.3 \%$ & $49.0 \%$ & $99.7 \%$ & $100 \%$ & & & & \\
\hline MRV4TND-AF368034_M2 & $51.3 \%$ & $50.6 \%$ & $51.3 \%$ & $50.6 \%$ & $49.3 \%$ & $49.1 \%$ & $49.3 \%$ & $49.8 \%$ & $91.2 \%$ & $91.5 \%$ & $100 \%$ & & & \\
\hline Nelson_bay-JF342676_M2 & $63.5 \%$ & $62.9 \%$ & $62.9 \%$ & $62.9 \%$ & $78.1 \%$ & $61.0 \%$ & $78.8 \%$ & $79.7 \%$ & $48.9 \%$ & $48.7 \%$ & $48.8 \%$ & $100 \%$ & & \\
\hline Pulau-JF342670_M2 & $63.0 \%$ & $62.5 \%$ & $62.1 \%$ & $62.3 \%$ & $79.2 \%$ & $61.8 \%$ & $78.8 \%$ & $94.2 \%$ & $49.7 \%$ & $49.6 \%$ & $49.9 \%$ & $79.7 \%$ & $100 \%$ & \\
\hline Bat_T3-JQ412759_M2 & $51.3 \%$ & $50.9 \%$ & $51.1 \%$ & $50.8 \%$ & $49.2 \%$ & $50.1 \%$ & $49.0 \%$ & $49.8 \%$ & $90.8 \%$ & $91.1 \%$ & $89.4 \%$ & $49.0 \%$ & $50.1 \%$ & $100 \%$ \\
\hline
\end{tabular}

important findings [9,15-17]. First, it further confirms the notion, derived from the topology of the S segment trees, that genetic reassortment may have occurred among the Malaka related orthoreoviruses [15,22-25]. Second, the Cangyuan virus M2 segment shared sequence identities of 95.0, 79.2, 79.2, and 78. $1 \%$ with the M2 segments of Kampar, Malaka, Pulau and Nelson Bay viruses, respectively (Table 2). The tree based on M2 segments indicates a great divergence of the Cangyuan and Kampar virus segments from those of the other three strains. This may suggest a new genotype represented by the Cangyuan and Kampar virus M2 segment [15]. The difference in sequence homology between segments of the reovirus strains suggested that genetic reassortment may have occurred among the bat-borne Melaka related orthoreoviruses.

\section{Conclusion}

In conclusion, phylogenetic analysis demonstrated that the Cangyuan virus was closely related to the Malaka and Kampar viruses and that a prevalence of Cangyuan virus-specific antibodies was present in fruit bat families circulating in Yunnan province, China. This further highlights the urgent need to systematically survey batborne viruses in south China so as to enable us to conduct more effective risk assessment, to provide forecast and devise better prevention and control strategies for potential future outbreaks.

\section{Methods}

Sample, serum and organ collection

Fifty fruit bats (Rousettus leschenaultia) were collected from across eight different locations in Cangyuan city of

Table 3 Homology comparison of Cangyuan virus's S1 gene segments nucleotide sequences with other fusogenic orthoreovirus

\begin{tabular}{|c|c|c|c|c|c|c|c|c|c|c|c|}
\hline \multirow[b]{2}{*}{ Cangyuan -KC994909_S1 } & \multicolumn{11}{|c|}{ Homology matrix of Cangyuan virus's S1 gene segments with other fusogenic orthoreovirus } \\
\hline & $100 \%$ & & & & & & & & & & \\
\hline Kampar_EU448334_S1 & $66.2 \%$ & $100 \%$ & & & & & & & & & \\
\hline Melaka_EF026043_S1 & $79.9 \%$ & $64.5 \%$ & $100 \%$ & & & & & & & & \\
\hline miyazaki- AB521793_S1 & $65.4 \%$ & $94.5 \%$ & $64.5 \%$ & $100 \%$ & & & & & & & \\
\hline Nelson_Bay_AF218360_S1 & $55.3 \%$ & $55.1 \%$ & $54.9 \%$ & $54.2 \%$ & $100 \%$ & & & & & & \\
\hline Pulau_AY357730_S1 & $94.7 \%$ & $66.9 \%$ & $79.4 \%$ & $66.1 \%$ & $55.3 \%$ & $100 \%$ & & & & & \\
\hline HK23629- EU165526-S1 & $70.5 \%$ & $64.2 \%$ & $70.0 \%$ & $65.0 \%$ & $53.3 \%$ & $69.8 \%$ & $100 \%$ & & & & \\
\hline HK46886- JF803294_S1 & $64.4 \%$ & $94.5 \%$ & $63.6 \%$ & $99.8 \%$ & $53.5 \%$ & $65.1 \%$ & $65.0 \%$ & $100 \%$ & & & \\
\hline HK50842- JF803295_S1 & $64.5 \%$ & $94.3 \%$ & $63.8 \%$ & $99.4 \%$ & $53.6 \%$ & $65.1 \%$ & $65.0 \%$ & $99.6 \%$ & $100 \%$ & & \\
\hline Sikamat- JF811580-S1 & $80.1 \%$ & $64.1 \%$ & $95.9 \%$ & $64.3 \%$ & $55.5 \%$ & $79.4 \%$ & $70.2 \%$ & $63.4 \%$ & $63.5 \%$ & $100 \%$ & \\
\hline Xi_river-GU188274_S1 & $56.1 \%$ & $55.0 \%$ & $56.1 \%$ & $54.4 \%$ & $65.4 \%$ & $54.8 \%$ & $53.8 \%$ & $53.4 \%$ & $53.6 \%$ & $55.9 \%$ & $100 \%$ \\
\hline
\end{tabular}




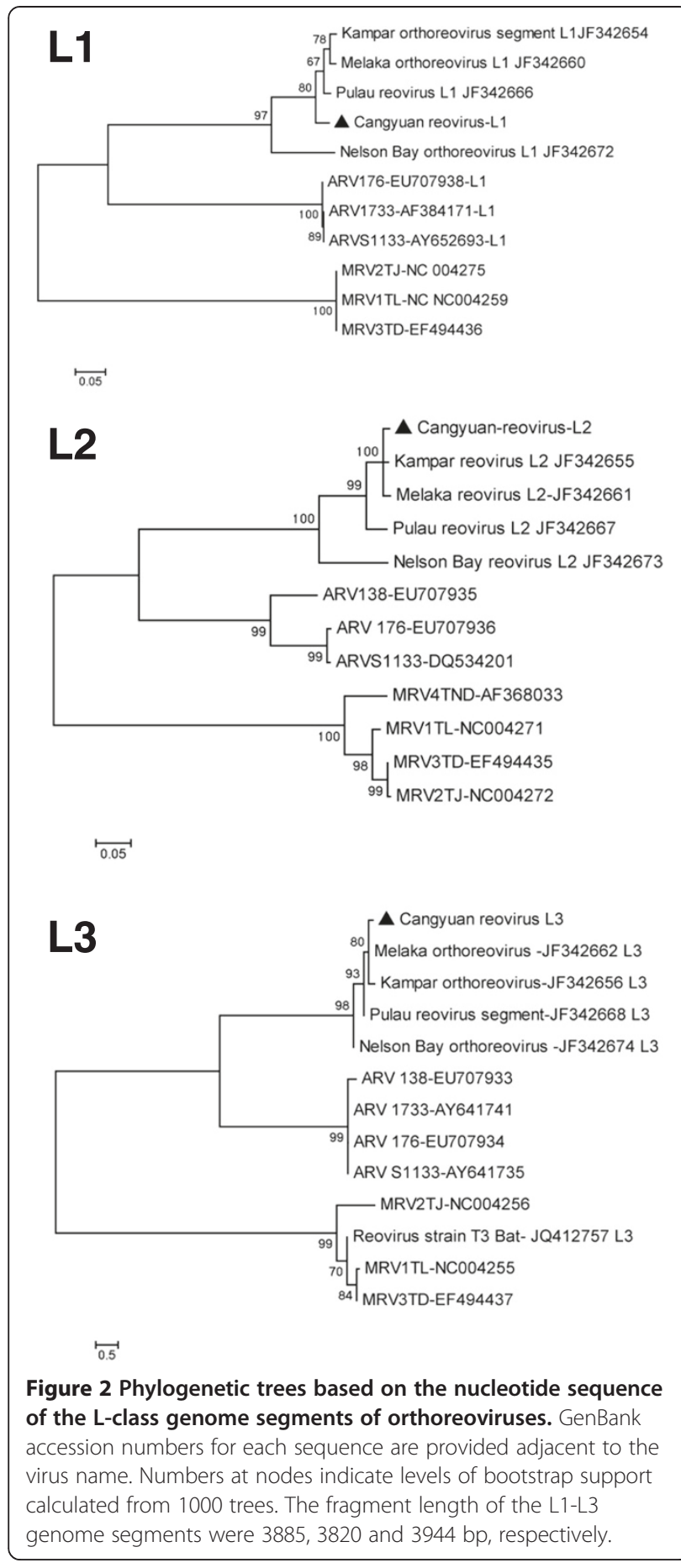

China's Yunnan province. All of the locations including three lychee, two mango orchards and three caverns were in close proximity to human residences. All bats were euthanized by intracardiac injection of sodium pentobarbital. Following euthanasia, serum samples were collected by cardiac puncture. The serum samples were used for neutralizing-antibody tests. Necropsies were performed directly following euthanasia. The necropsy findings
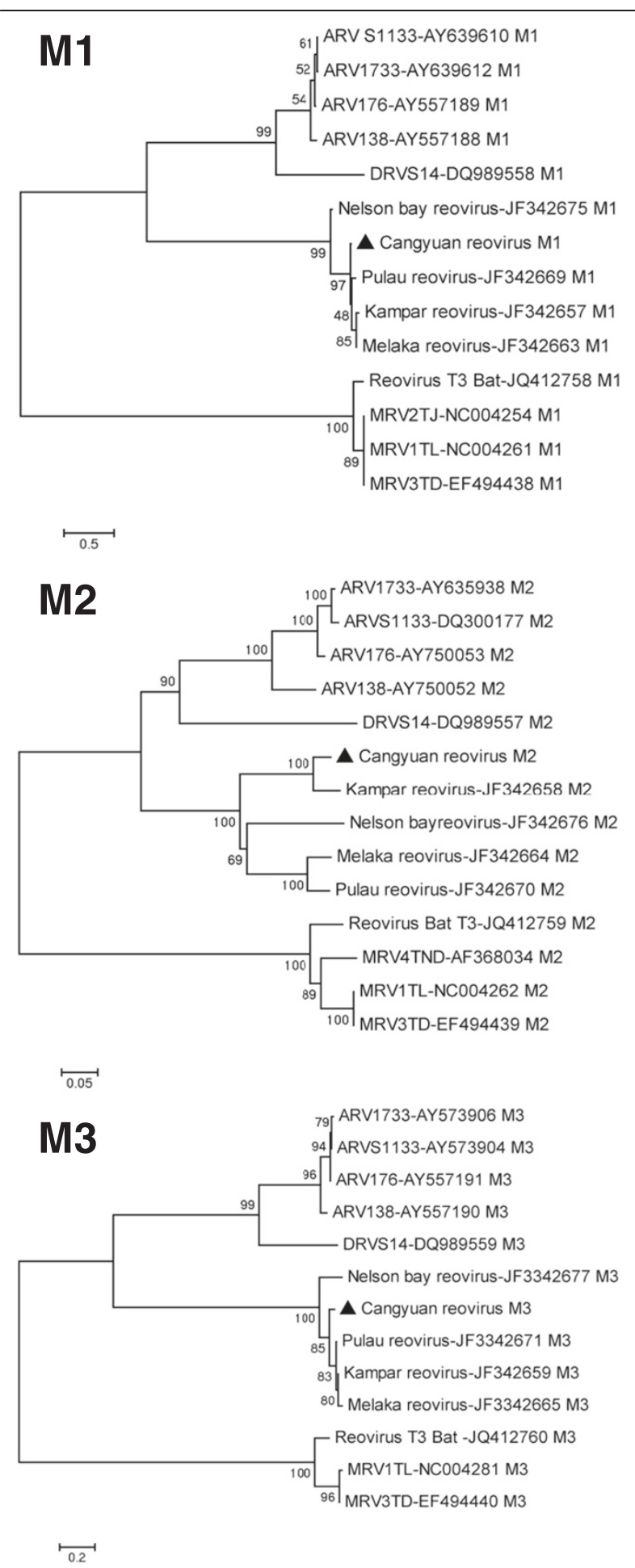

Figure 3 Phylogenetic trees based on the nucleotide sequence of the M-class genome segments of orthoreoviruses. GenBank accession numbers for each sequence are provided adjacent to the virus name. The fragment length of the M1-M3 genome segments were 2277, 2134 and 1983 bp, respectively. Numbers at nodes indicate levels of bootstrap support calculated from 1000 trees. 

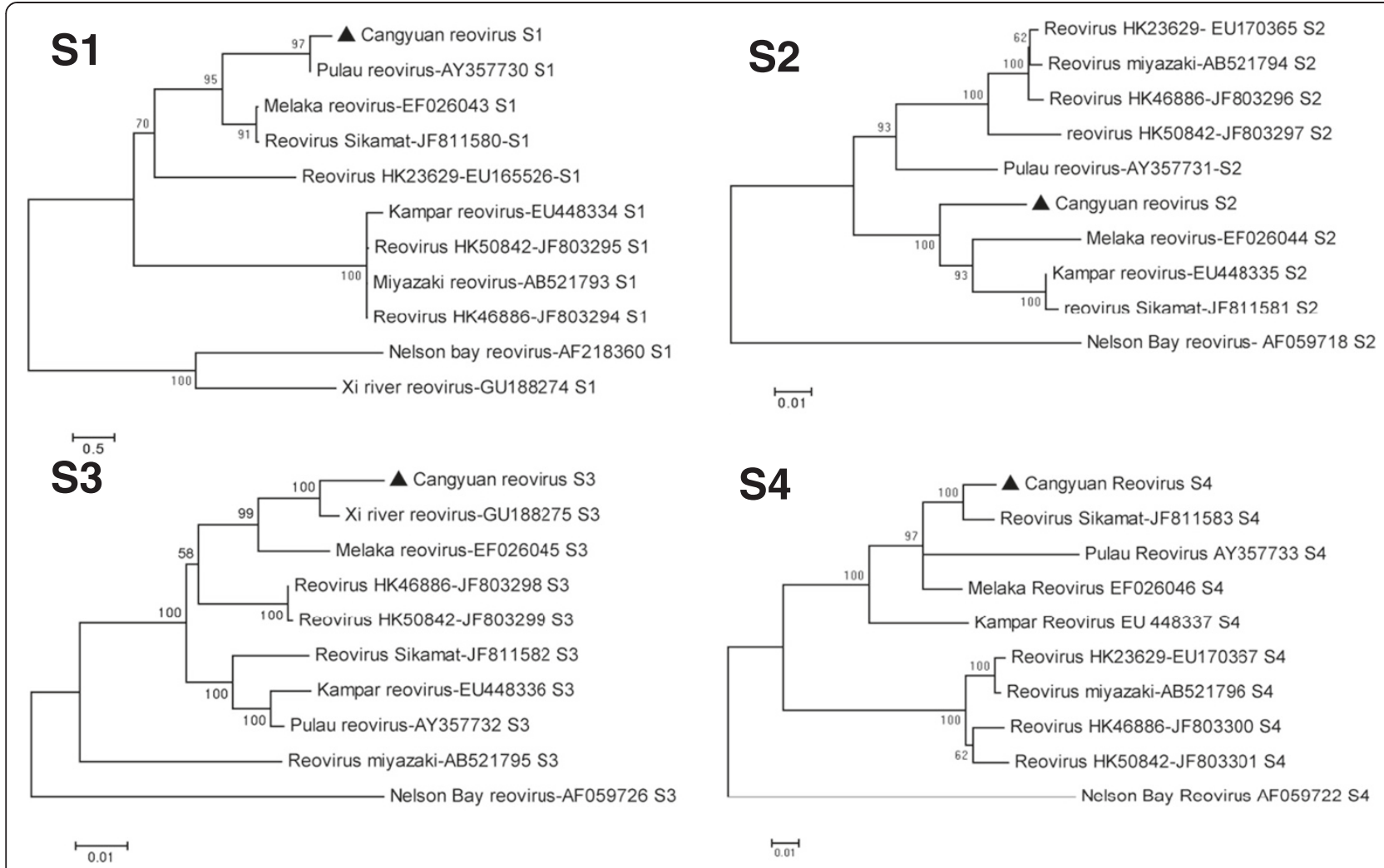

Figure 4 Phylogenetic trees based on the nucleotide sequence of the S-class genome segments of orthoreoviruses. GenBank accession numbers for each sequence are provided adjacent to the virus name. The fragment length of the S1-S4 genome segments were 1596, 1323,1180 and $1184 \mathrm{bp}$, respectively. Numbers at nodes indicate levels of bootstrap support calculated from 1000 trees.

demonstrated that these bats were apparently healthy and no special pathological lesions was observed (data not show). The intestine samples were used for virus isolation and the kidney, heart, lung, liver, spleen, rectal swab and brain samples were processed for PCRs testing. The tissue samples stored at $-80^{\circ} \mathrm{C}$.

\section{Ethics statement}

All procedures using animals were approved by the Animal Care and Use Committees of Centre for Disease Control and Prevention, Chengdu Military Region and were in compliance with the China Animal Welfare Act. We state clearly that no specific permissions were required for these locations/activities and confirm that the field studies did not involve endangered or protected species.

\section{Virological investigation}

Virus isolation was carried out in Vero E6 cells. To refer [23], kohl et al [26], Vero E6 cells were maintained at $37^{\circ} \mathrm{C}$ with $5 \% \mathrm{CO}_{2}$ unless stated otherwise. Cells were seeded into 24-well cell-culture plates and incubated overnight until 80-90\% confluent. For infection, homogenates of the intestine samples for each bat were centrifuged at low- speed $(6,000 \times \mathrm{g})$ for $10 \mathrm{~min}$ at $4^{\circ} \mathrm{C}$, treated with 100,000 $\mathrm{U} / \mathrm{ml}$ penicillin and $100 \mu \mathrm{g} / \mathrm{ml}$ streptomycin, and then inoculated into Vero E6 cells for 1 hour under standard cellculture conditions and washed the cells three times with PBS (phosphate buffer saline) after inoculation. The infected cells were sub-cultured three times and observed daily for the occurrence of cytopathic effects (CPE). Upon $\mathrm{CPE}$ in the third subcultivation, the supernatant was passaged in $80-90 \%$ confluent fresh Vero cells in a $175 \mathrm{~cm}^{2}$ flask for one week. Aliquots were stored at $-80^{\circ} \mathrm{C}$. One aliquot was titrated on Vero E6 cells to estimate the viral titer. After the second passage, Virus titrations were performed by end-point titration in VeroE6 cells and the TCID50/0.1 ml was calculated from 5 replicates by the method of Spearman-Karber.

\section{Identification of virus by electron microscopy (EM)}

Cangyuan virus was observed by EM. For negative staining, paraformaldehyde-fixed (2\%) purified Cangyuan virus was adsorbed onto carbon-coated parlodion-filmed nickel grids and negatively stained with $2 \%$ phosphotungstic acid. Specimens were examined using a transmission electron microscope (Hitachi-8100, Japan) at $80 \mathrm{kV}$. 


\section{VIDISCR, PCR, nucleotide sequencing, and phylogenetic analysis}

Culture supernatants of Cangyuan virus was analyzed by VIDISCR. Virus particles were harvested from cells by three freeze-thaw cycles and the resulting suspension purified from cell debris by low-speed centrifugation. Nucleic acids were extracted using the AxyPrep Body Fluid Viral DNA/RNA Miniprep Kit (Axygen, Inc.). Reverse transcription of the viral RNA was performed by using the RevertAid ${ }^{\mathrm{TM}}$ First Strand cDNASynthesis Kit (Fermentas, Inc). The VIDISCR assay was performed as previously described [27]. To further characterize the virus and its phylogeny primers were designed with Primer Premier 5.0 based on published sequences selective for the 10 genome segments of Melaka virus and other orthoreoviruses (Additional file 4: Table S4) [9,16]. Each of the 10 genome segments were amplified using the pfu PCR Polymerase Kit (Fermentas, Inc) with the primers as listed in Additional file 4: Table S4. Reverse transcription PCR was performed as described $[9,16]$. The amplicons were visualized using $2 \%$ agarose gel electrophoresis. PCR products were sequenced after cloning by using CloneJET ${ }^{\text {тм }}$ PCR cloning kit (Fermentas, Inc). Sequence alignment was conducted using DNAMAN5.0 and phylogenetic analysis of the whole Cangyuan virus genome sequences of all L, M and $\mathrm{S}$ segments were performed by the neighbor-joining method using MEGA6 software (www.megasoftware.net). The Phylogenetic data have been deposited in TreeBase (Study Accession URL: http://purl.org/phylo/treebase/phylows/ study/TB2:S16635). RT-QPCRs testing were repeated on the 50 fruit bats original samples including the Kidney, heart, lung, liver, spleen, intestine, rectal swab sample, and brain samples with the L2 segment primers (CY-L2QF1: 5' GCA ATG CCG AAT ATC TAA AGC 3', CY-L2QR1:5' AGA GCA AGA GCC CAA ATG AA 3'). The reaction was performed using the One Step $\mathrm{SYBR}^{\circ}$ PrimeScript ${ }^{\mathrm{Tm}}$ PLUS RT-PCR Kit (TAKARA BIOTECHNOLOGY (Dalian) CO., LTD) by lightcycler2.0 (Roche). To test the viral growth curve of the Cangyuan virus, the virus samples were harvested at 2, 4, 8, 12, 16, 20, 24 and 28 hours after infection and quantified with the already established RT-QPCR. To test whether the Cangyuan virus is the virus (or one of the viruses) replicating in the cells and responsible for the observed CPE, the culture supernatants $0.1 \mathrm{~mL}$ (after the second passage,105.5 TCID50/0.1 mL titer) was serially diluted until $10^{-3}$ and infected Vero E6 cells. After the 24 hours, the culture supernatants were analyzed by RT-QPCRs with the L2 segment primers.

\section{Virus neutralization test}

To refer the Chua's report [9], Serum samples from each bat were screened for anti-Cangyuan virus neutralizing antibody. Serum, the negative control (fetal calf serum, FCS), virus, and cell controls were included in the assay.
Serial 2-fold dilutions (1:10 to 1:640) of control and fruit bat sera were prepared in duplicate. An equal volume of Cangyuan virus working stock containing 150 TCID50 was added to the diluted sera and incubated for 1 hour. The preincubated virus/serum mix was added to 80$90 \%$ confluent Vero cell monolayers. After 1 hour of virus adsorption, the inoculum was removed, the monolayers washed three times with 2\%FCS MEM, and fresh media added. All incubations were performed under standard cell culture conditions. Vero cell monolayers were observed for CPE 3 days post-inoculation. The ability of sera to neutralize virus was determined by scoring the extent of CPE observed for duplicate wells.

\section{Additional files}

Additional file 1: Table S1. Homology comparison of Cangyuan virus's $L$ gene segments nucleotide sequences with other fusogenic orthoreovirus.

Additional file 2: Table S2. Homology comparison of Cangyuan virus's $\mathrm{M}$ gene segments nucleotide sequences with other fusogenic orthoreovirus.

Additional file 3: Table S3. Homology comparison of Cangyuan virus's $\mathrm{S}$ gene segments nucleotide sequences with other fusogenic orthoreovirus.

Additional file 4: Table S4. Primers used to amplify the 10 gene segments of fusogenic orthoreovirus and the GenBank accession numbers of Orthoreovirus strain Cangyuan.

\section{Competing interests}

The authors declare that they have no competing interests.

\section{Authors' contributions}

$\mathrm{TH}, \mathrm{WQ}$ and $\mathrm{BH}$ participated in the design and conducted the majority of the experiments in the study and drafted the manuscript. $Y Z, J Y, X L$ and $W Z$ carried out the molecular genetic studies, participated in the sequence alignment. GC, YZ, YW and YZ contributed to the interpretation of the findings and revised the manuscript. ZF, YH and WZ performed the analyses of transmission electron microscope. CT, QF and FZ participated in the design of the study and performed the statistical analysis. All authors read and approved the final manuscript.

\section{Acknowledgments}

We thank Ms. Ming Qing for her administrative assistance. This work was financially sponsored by the National Natural Science Foundation of China-Yunnan Province Joint Fund (U1036601), the key program (AWS11L009), and the youth fund program (81101618) from the National Natural Science Foundation of China.

\section{Author details}

${ }^{1}$ Centre for Disease Control and Prevention, Chengdu Military Region, 168 Daguan Road, Kunming 650032, China. ${ }^{2}$ Institute of Military Veterinary, Academy of Military Medical Sciences, Changchun 130062, China.

${ }^{3}$ Department of Biochemistry and Molecular Biology, Fudan University Shanghai Medical College, Shanghai 200030, China. ${ }^{4}$ The Animal Epidemic Disease Control Center, Kunming 650032, Yunnan Province, China. ${ }^{5}$ General Hospital of Chengdu Military Region of PLA, Chengdu 610083, China.

Received: 27 August 2014 Accepted: 11 November 2014

Published online: 30 November 2014

\section{References}

1. Drosten C, Günther S, Preiser W, van der Werf S, Brodt HR, Becker S, Rabenau H, Panning M, Kolesnikova L, Fouchier RA, Berger A, Burguière AM, 
Cinatl J, Eickmann M, Escriou N, Grywna K, Kramme S, Manuguerra JC, Müller S, Rickerts V, Stürmer M, Vieth S, Klenk HD, Osterhaus AD, Schmitz H, Doerr HW: Identification of a novel coronavirus in patients with severe acute respiratory syndrome. N Engl J Med 2003, 348(20):1967-1976.

2. Guan $Y$, Zheng BJ, He YQ, Liu XL, Zhuang ZX, Cheung CL, Luo SW, Li PH, Zhang LJ, Guan YJ, Butt KM, Wong KL, Chan KW, Lim W, Shortridge KF, Yuen KY, Peiris JS, Poon LL: Isolation and characterization of viruses related to the SARS coronavirus from animals in southern China. Science 2003, 302(5643):276-278.

3. Wong S, Lau S, Woo P, Yuen KY: Bats as a continuing source of emerging infections in humans. Rev Med Virol 2007, 17(2):67-91.

4. Calisher $\mathrm{CH}$, Childs JE, Field HE, Holmes KV, Schountz T: Bats: important reservoir hosts of emerging viruses. Clin Microbiol Rev 2006, 19(3):531-545.

5. Tong S, Li Y, Rivailler P, Conrardy C, Castillo DA, Chen LM, Recuenco S, Ellison JA, Davis CT, York IA, Turmelle AS, Moran D, Rogers S, Shi M, Tao Y, Weil MR, Tang K, Rowe LA, Sammons S, Xu X, Frace M, Lindblade KA, Cox $\mathrm{NJ}$, Anderson $\amalg$, Rupprecht $C E$, Donis RO: A distinct lineage of influenza $A$ virus from bats. Proc Natl Acad Sci U S A 2012, 109(11):4269-4274.

6. Xia L, Fan Q, He B, Xu L, Zhang F, Hu T, Wang Y, Li N, Qiu W, Zheng Y, Matthijnssens J, Tu C: The complete genome sequence of a G3P [10] Chinese bat rotavirus suggests multiple bat rotavirus inter-host species transmission events. Infect Genet Evol 2014, 28C:1-4.

7. He B, Zhang F, Xia L, Hu T, Chen G, Qiu W, Fan Q, Feng Y, Guo H, Tu C: Identification of a novel orthohepadnavirus in pomona roundleaf bats in China. Arch Virol 2014. doi:10.1007/s00705-014-2222-0.

8. He B, Fan Q, Yang F, Hu T, Qiu W, Feng Y, Li Z, Li Y, Zhang F, Guo H, Zou X, Tu C: Hepatitis virus in long-fingered bats. Myanmar Emerg Infect Dis 2013, 19(4):638-640

9. Chua KB, Crameri G, Hyatt A, Yu M, Tompang MR, Rosli J, McEachern J, Crameri S, Kumarasamy V, Eaton BT, Wang LF: A previously unknown reovirus of bat origin is associated with an acute respiratory disease in humans. Proc Natl Acad Sci U S A 2007, 104(27):11424-11429.

10. Nibert ML: Structure of mammalian orthoreovirus particles. Curr Top Microbiol Immunol 1998, 233(Pt 1):1-30.

11. Nibert ML, Schiff LA, Fields BN: Mammalian reoviruses contain a myristoylated structural protein. J Virol 1991, 65(4):1960-1967.

12. Pritchard LI, Chua KB, Cummins D, Hyatt A, Crameri G, Eaton BT, Wang LF: Pulau virus; a new member of the Nelson Bay orthoreovirus species isolated from fruit bats in Malaysia. Arch Virol 2006, 151(2):229-239.

13. Thalmann CM, Cummins DM, Yu M, Lunt R, Pritchard LI, Hansson E, Crameri S, Hyatt A, Wang LF: Broome virus, a new fusogenic Orthoreovirus species isolated from an Australian fruit bat. Virology 2010, 402(1):26-40.

14. Duncan R: Extensive sequence divergence and phylogenetic relationships between the fusogenic and nonfusogenic orthoreoviruses: a species proposal. Virology 1999, 260(2):316-328.

15. Voon K, Chua KB, Yu M, Crameri G, Barr JA, Malik Y, Wang LF: Evolutionary relationship of the $\mathrm{L}$ - and $\mathrm{M}$-class genome segments of bat-borne fusogenic orthoreoviruses in Malaysia and Australia. J Gen Virol 2011, 92(Pt 12):2930-2936.

16. Chua KB, Voon K, Crameri G, Tan HS, Rosli J, McEachern JA, Suluraju S, Yu M, Wang LF: Identification and characterization of a new orthoreovirus from patients with acute respiratory infections. PLoS One 2008, 3(11):e3803.

17. Chua KB, Voon K, Yu M, Keniscope C, Abdul Rasid K, Wang LF: Investigation of a potential zoonotic transmission of orthoreovirus associated with acute influenza-like illness in an adult patient. PLoS One 2011, 6(10):e25434.

18. Du L, Lu Z, Fan Y, Meng K, Jiang Y, Zhu Y, Wang S, Gu W, Zou X, Tu C: X River virus, a new bat reovirus isolated in southern China. Arch Virol 2010, 155(8):1295-1299.

19. Cheng P, Lau CS, Lai A, Ho E, Leung P, Chan F, Wong A, Lim W: A novel reovirus isolated from a patient with acute respiratory disease. $J$ Clin Virol 2009, 45(1):79-80.

20. Wong AH, Cheng PK, Lai MY, Leung PC, Wong KK, Lee WY, Lim WW: Virulence potential of fusogenic orthoreoviruses. Emerg Infect Dis 2012, 18(6):944-948

21. Gard G, Compans RW: Structure and cytopathic effects of Nelson Bay virus. J Virol 1970, 6(1):100-106.

22. Ahmed R, Fields BN: Reassortment of genome segments between reovirus defective interfering particles and infectious virus: construction of temperature-sensitive and attenuated viruses by rescue of mutations from DI particles. Virology 1981, 111(2):351-363.
23. Liu HJ, Lee LH, Hsu HW, Kuo LC, Liao MH: Molecular evolution of avian reovirus: evidence for genetic diversity and reassortment of the S-class genome segments and multiple cocirculating lineages. Virology 2003, 314(1):336-349.

24. Shen PC, Chiou YF, Liu HJ, Song CH, Su YP, Lee LH: Genetic variation of the lambdaA and lambdaC protein encoding genes of avian reoviruses. Res Vet Sci 2007, 83(3):394-402.

25. Su YP, Su BS, Shien JH, Liu HJ, Lee LH: The sequence and phylogenetic analysis of avian reovirus genome segments $M 1, M 2$, and $M 3$ encoding the minor core protein muA, the major outer capsid protein muB, and the nonstructural protein muNS. J Virol Methods 2006, 133(2):146-157.

26. Kohl C, Lesnik R, Brinkmann A, Ebinger A, Radonic A, Nitsche A, Muhldorfer K, Wibbelt $G$, Kurth A: Isolation and characterization of three mammalian orthoreoviruses from European bats. PLOS One 2012, 7(8):e43106.

27. Hu T, Zheng Y, Zhang Y, Li G, Qiu W, Yu J, Cui Q, Wang Y, Zhang C, Zhou X, Feng Z, Zhou W, Fan Q, Zhang F: Identification of a novel Getah virus by Virus-Discovery-cDNA random amplified polymorphic DNA (RAPD). BMC Microbiol 2012, 12:305

doi:10.1186/s12866-014-0293-4

Cite this article as: Hu et al:: Characterization of a novel orthoreovirus isolated from fruit bat, China. BMC Microbiology 2014 14:293.

\section{Submit your next manuscript to BioMed Central and take full advantage of:}

- Convenient online submission

- Thorough peer review

- No space constraints or color figure charges

- Immediate publication on acceptance

- Inclusion in PubMed, CAS, Scopus and Google Scholar

- Research which is freely available for redistribution

Submit your manuscript at www.biomedcentral.com/submit
C BioMed Central 